\title{
Cervicofacial lymphatic malformations: diagnosis and management
}

\author{
Rachida Bouatay ${ }^{1,2^{*}}$, Badii Hmida ${ }^{2,3}$, Malek Hajjej ${ }^{1}$, Amira Farhati ${ }^{1}$, Khaled Harrathi ${ }^{1,2}$, Naourez Kolsi ${ }^{1,2}$ and \\ Jamel Koubaa ${ }^{1,2}$
}

\begin{abstract}
Background: Lymphatic malformations are rare benign tumors that result from congenital and acquired alterations of the lymphatic vessels. They occur most commonly on the head and neck region.

The aim of this study is to describe clinical profiles of lymphatic malformations of the head and neck (LMHN) as well as to study therapeutic modalities through our series and review of the literature.

Results: This is a retrospective record-based descriptive study conducted in the ENT and the Radiology departments over a 17-year period. Our study included twelve patients, aged between 8 months and 52 years. Two swellings were present at birth and had not been prenatally diagnosed in both cases. One patient was affected by TRISOMY 21. All patients consulted for a painless mass of the head or neck. Seven masses were located in the suprahyoid region and five in the infrahyoid region. Ultrasonography, computed tomography $(C T)$, and magnetic resonance imaging (MRI) were realized to establish the diagnosis and assess the extent of the lesions.

Surgical excision was performed in 7 patients. It was complete in 6 patients. Five patients were treated with sclerotherapy. The sclerosing agents used were Aetoxisclerol $2 \%$, hypertonic saline, and absolute alcohol. One patient had a reversible paresis of the left mental nerve after surgery. An excellent response to sclerotherapy with complete resolution was obtained in 3 cases with no recurrence of the disease.
\end{abstract}

Conclusions: Surgical excision has been the management option of choice for LMHN. The recent advances in sclerotherapy make it safe and effective as a primary treatment modality for these lesions.

Keywords: Lymphatic malformations, Cervicofacial, Imaging, Surgery, Sclerotherapy

\section{Background}

Lymphatic malformations (LM) are rare benign tumors that result from congenital and acquired alterations of the lymphatic vessels. They occur most commonly on the head and neck region. Typically, LMHN are noted before birth, at birth, or in the first few months of life in fewer than $50 \%$ of cases and by the age of 2 years in $80-$ $90 \%$ of cases [1].

The management of cervicofacial lymphatic malformations (CFLM) remains difficult despite a large therapeutic arsenal. Complete surgical excision remains the treatment

\footnotetext{
*Correspondence: rbouattay@yahoo.fr

${ }^{1}$ ENT Department at Fattouma Bourguiba Hospital, Monastir, Tunisia

University of Monastir, Monastir, Tunisia

Full list of author information is available at the end of the article
}

of reference. However, many recent reports have increasingly documented remarkable results for the management of such lesions with sclerosing agents.

The primary aims of this current study were to describe the clinical profiles of CFLM as well as to study the methods of therapeutic management and evolutionary particularities of this type of lesions through our series and review of the literature.

\section{Methods}

We conducted a retrospective record-based descriptive study in the ENT and the Radiology departments over a 17 -year period (from 2002 to 2018) including 12 patients with CFLM.

\section{Springer Open}

(c) The Author(s). 2021 Open Access This article is licensed under a Creative Commons Attribution 4.0 International License, which permits use, sharing, adaptation, distribution and reproduction in any medium or format, as long as you give appropriate credit to the original author(s) and the source, provide a link to the Creative Commons licence, and indicate if changes were made. The images or other third party material in this article are included in the article's Creative Commons licence, unless indicated otherwise in a credit line to the material. If material is not included in the article's Creative Commons licence and your intended use is not permitted by statutory regulation or exceeds the permitted use, you will need to obtain permission directly from the copyright holder. To view a copy of this licence, visit http://creativecommons.org/licenses/by/4.0/. 
The identification of cases was done by reviewing the medical records of the ENT and Radiology departments and through our outpatients' data focusing on the age of onset, primary reason for consultation, associated signs, location of lesion, characteristics of the swelling, radiologic investigation performed, treatment modality used, complications encountered, and results achieved. No exclusion criteria in terms of age, gender, and comorbidity were applied.

This is a retrospective study approved by our institutional ethics committee IORG 0009738/0990-0279, who also certified that patient findings have no ethical issues to be published.

\section{Results}

A total of 12 cases of CFLM were identified. They were aged 8 months to 52 years with a median age of 13.5 years old at the first consultation. The swelling was present at birth in 2 patients which had not been prenatally diagnosed in both of them. Seven patients (58\%) were females and five (42\%) were males with a sex ratio of 0.71. No family history, similar cases, or other LM were found. Our study included one patient with Trisomy 21.

All the patients consulted after noticing a painless mass that caused disfigurement. The time to first consultation varied from 2 months to 11 years. Two patients presented with mild dyspnea and one patient with speech problems. There was an equal distribution between the right and left sides. The location was suprahyoid in 7 cases (58.3\%) and infrahyoid in 5 cases (41.7\%). The suprahyoid locations were submaxillary, parotid, and the floor of the mouth (Fig. 1). For the infrahyoid ones, they were subclavicular and cervical. One patient had two swellings: submaxillary and in the floor of the mouth (Table 1). The swelling was firm in 8 cases, soft in 3 cases, and elastic in one case. All the

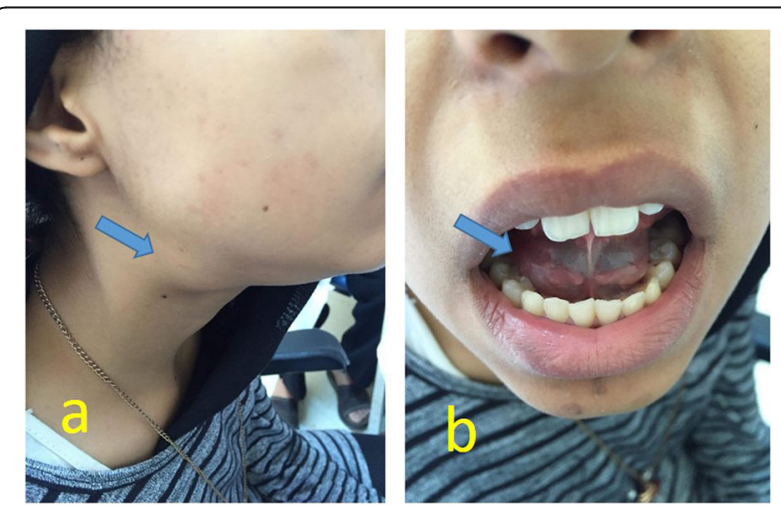

Fig. 1 A patient with two cystic lymphangiomas: right submaxillary (a) and in the right side of the floor of the mouth
Table 1 Distribution of lesions according to location

\begin{tabular}{lll}
\hline Malformation location & Number of cases \\
\hline Suprahyoid location & Parotid & 4 \\
& Submaxillary & 3 \\
& Floor of the mouth & 1 \\
Infrahyoid location & Subclavicular & 2 \\
& Neck & \\
& Posterior triangle & 2 \\
& Laterocervical & 1 \\
\hline
\end{tabular}

masses were mobile, painless, and covered with normal skin.

B-mode ultrasonography and color Doppler ultrasound were performed in 10 patients to accurately characterize the nature of the lesions. The cysts' major axis ranged from 22 to $65 \mathrm{~mm}$ with an average size of $43 \mathrm{~mm}$. All the lesions included in the present study were macrocystic lymphangiomas. Seven patients had anechoic masses and the other 3 patients showed heterogeneous echogenicity. Cyst vascularity was evaluated by color Doppler imaging which showed two vascularized LM. Lesions were multilocular in 9 cases (75\%) and unilocular in 3 cases (25\%).

Computed tomography $(\mathrm{CT})$ was realized in $3 \mathrm{pa}$ tients. All of these 3 masses were hypodense with a homogeneous internal density. No fluid-fluid level was detected.

MRI was performed in six cases. MRI sequences without intravenous contrast administration showed all masses as hypo-intense on T1-weighted (T1W) sequences and hyperintense on T2-weighted (T2W) sequences. After gadolinium injection, only the walls and the internal septa showed contrast enhancement in 5 patients (Figs. 2 and 3).

Management options in our study included surgical excision and sclerotherapy. The average time between first consultation and first management was 4.5 months. During that period, no patient showed a spontaneous regression. Two patients were lost to follow-up. In the 10 remaining patients, the average follow-up period was 5.6 years.

Surgical excision was performed in 7 patients (Table 2). It was complete in 6 patients. A final histopathological analysis confirmed the diagnosis in all patients of this group. Complete improvement was seen in the 5 patients who had total surgical removal, and only the patient who underwent partial removal had a submaxillary recurrence 6 months after his surgery. He showed a spontaneous regression of the recurrent lesion after 6 months. The seventh patient was lost to follow-up after surgery. A reversible paresis of the 


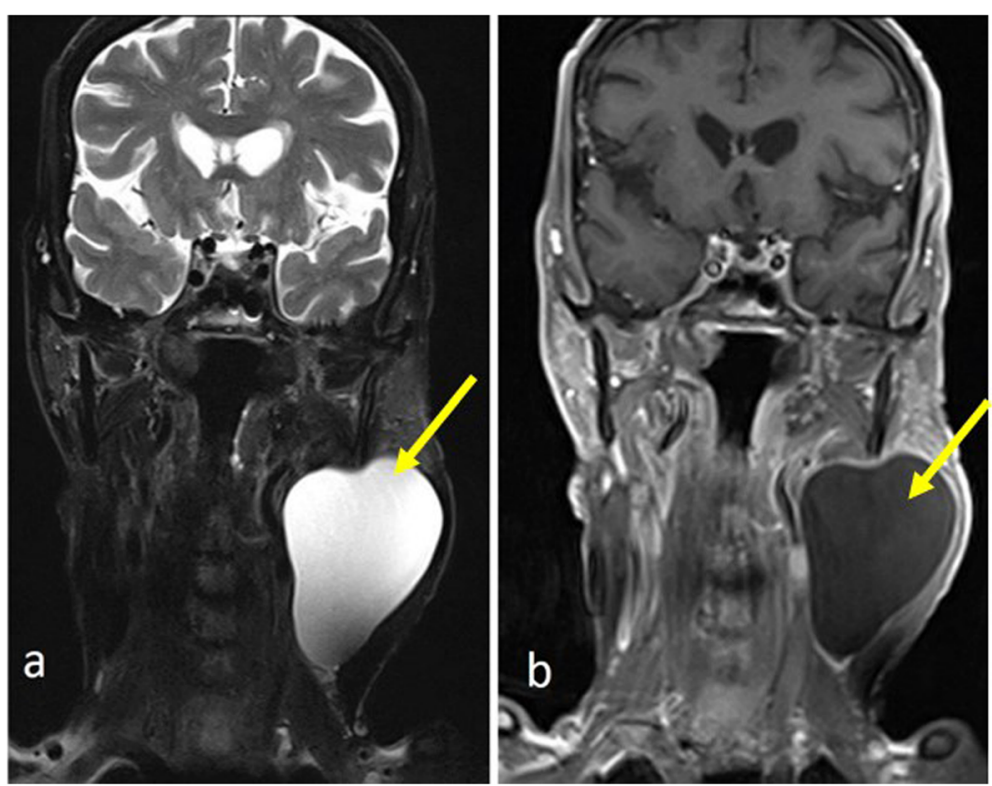

Fig. 2 Cervical MRI; coronal T2W sequence (a) and coronal T1W sequence after gadolinium injection (b): hyper-intense formation on T2W, hypointense on T1W without internal enhancement after gadolinium administration

left mental nerve was encountered in one patient. She had a left submaxillary lesion. No fluid collection in the resection site was encountered during the study period.

Five patients were treated with sclerotherapy. The sclerosing agents used in our patients were Aetoxisclerol $2 \%$, hypertonic saline solution, and absolute alcohol (Tables 3 and 4).
All the sessions of sclerotherapy were performed under general anesthesia. The number of sclerosing agent injections varied from one to two injections with an average of 1.4 injections. An excellent response with complete resolution was noted in 3 cases with no recurrence of the disease. The first patient demonstrated a complete regression after only one injection of

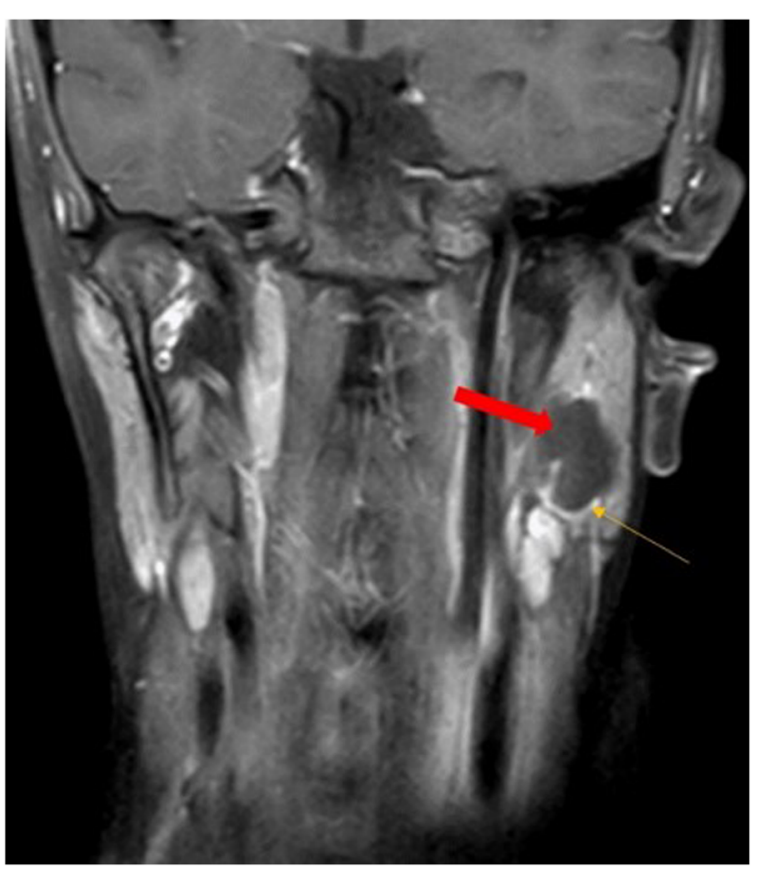

Fig. 3 Cervical MRI; coronal T1W sequence after gadolinium injection: nonenhancing cystic formation ( 
Table 2 Clinical profiles and response to treatment in our patients treated surgically

\begin{tabular}{|c|c|c|c|c|c|c|c|c|}
\hline Case number & Age of onset & Sex & $\begin{array}{l}\text { Time to } 1 \text { st } \\
\text { consultation }\end{array}$ & Location & Lesion size $(\mathrm{mm})$ & Resection & Follow-up & Recurrence \\
\hline 1 & 26 years & Female & 3 months & Left parotid & $43 \times 38$ & Complete & 3 years & No \\
\hline 2 & 52 years & Male & 4 months & Right posterior triangle & $44 \times 30$ & Complete & 2 years & No \\
\hline 3 & At birth & Female & 11 years & Left submaxillary & $22 \times 13$ & Complete & 16 years & No \\
\hline 4 & 39 years & Male & 12 months & Right subclavicular & $65 \times 50$ & Complete & 6 years & No \\
\hline 5 & 9 years & Male & 6 months & Right submaxillary & $55 \times 37$ & Partial & 10 years & $\begin{array}{l}\text { Yes (6 months } \\
\text { after surgery) }\end{array}$ \\
\hline 6 & 30 years & Female & 12 months & Left subclavicular & $36 \times 20$ & Complete & 11 years & No \\
\hline 7 & 5 months & Male & 3 months & Left posterior triangle & $35 \times 23$ & Complete & Lost to follow-up & No \\
\hline
\end{tabular}

Aetoxisclerol alone and the two remaining patients after 2 injections of Aetoxisclerol associated with hypertonic saline. One of these five patients demonstrated a good response with minimal residual after 2 injections of absolute alcohol. The fifth was lost to follow-up after her first session of sclerotherapy. The response to sclerotherapy was evaluated relying on clinical and control based on an ultrasound done 1 month after sclerotherapy and 3 months later (Fig. 4).

Complications included mild temperature elevation in one patient during the first $24 \mathrm{~h}$ after injection which was easily treated with paracetamol, local inflammatory reaction after the first injection in one patient, and intracystic hemorrhage in one patient causing sudden enlargement of the lesion.

\section{Discussion}

This present work was interested in describing clinical profiles of CFLM as well as studying therapeutic modalities through our series and review of the literature. Our results showed that the diagnosis of these lesions is established by clinical exam and imaging and that sclerotherapy of these lesions is associated with satisfactory to excellent results and present so a good alternative to surgery.

LM can manifest anywhere in the body, but most frequently involve the head and neck with over $75 \%$ of all the cases. About $50-60 \%$ of these lesions are identified at birth, while $80-90 \%$ are diagnosed by the end of the second year of life [2]. CFLM can be identified in utero by carrying out a routine prenatal ultrasonography [3]. They are rarely observed in adults, secondary to infections, neoplasms, trauma, and iatrogenic injuries [4]. In our study, no lesions were identified in utero, 2 swellings were present at birth, and five patients were under 2 years old.

The sex ratio varied from 0.6 to 2.8 [5, 6]. Our study included 5 males and 7 females with a sex ratio of 0.71 . This discrepancy was due to the paucity of this lesion and the size of the samples. Several congenital malformation syndromes have been reported in association with these lesions, including Turner's syndrome, Noonan's syndrome, and several chromosomal aneuploidies. Some authors reported that isolated lymphatic malformations can be inherited as an autosomal recessive disorder [7]. Only one patient with Trisomy 21 was defined in our series.

The most common presenting symptom is a progressively enlarging painless and asymptomatic mass of the head and neck. The usual slow progressive growth of the swelling coupled with the absence of early pressure symptoms may explain the reason for the late presentation [8]. Obstructive symptoms may develop due to mass effect when the lesions enlarge and compress the surrounding vital structures [4]. All patients of the present study consulted after noticing a painless mass that caused disfigurement. It was associated with dyspnea in two patients and speech problems in one patient.

Concerning the involved site, the most common location is the posterior cervical area [9]. Some authors suggested that this type of lesions has a predilection for the left side of the head and neck, most likely because the thoracic duct enters the subclavian vein on the left [10]. The parotid region was the most common site of

Table 3 The sclerosing agents used and their doses

\begin{tabular}{lll}
\hline Sclerosing agent & Dose & Number of cases \\
\hline Aetoxisclerol $2 \%$ & One ampoule of $2 \mathrm{ml}$ contains $40 \mathrm{mg}$ Lauromacrogol & 4 \\
Absolute alcohol & $0.01 \mathrm{ml} / \mathrm{kg}$ of body weight & 1 \\
Hypertonic saline & $1 \mathrm{ml}$ with every ampoule of Aetoxisclerol 2\% & 3 \\
\hline
\end{tabular}


Table 4 Clinical profiles and response to treatment in our patients treated with sclerotherapy

\begin{tabular}{|c|c|c|c|c|c|c|c|c|c|}
\hline $\begin{array}{l}\text { Case } \\
\text { number }\end{array}$ & $\begin{array}{l}\text { Age of } \\
\text { onset }\end{array}$ & Sex & $\begin{array}{l}\text { Time to 1st } \\
\text { consultation }\end{array}$ & Location & $\begin{array}{l}\text { Lesion size } \\
(\mathrm{mm})\end{array}$ & Sclerosing agent & $\begin{array}{l}\text { Number of } \\
\text { injections }\end{array}$ & Follow-up & $\begin{array}{l}\text { Response to } \\
\text { treatment }\end{array}$ \\
\hline 8 & $\begin{array}{l}12 \\
\text { years }\end{array}$ & Female & 2 months & $\begin{array}{l}\text { Right submaxillary and } \\
\text { floor of the mouth }\end{array}$ & $\begin{array}{l}50 \times 35 \\
30 \times 21\end{array}$ & Aetoxisclerol 2\% & 1 & 15 months & $\begin{array}{l}\text { Complete } \\
\text { resolution }\end{array}$ \\
\hline 9 & 7 years & Male & 5 years & Left parotid & $62 \times 55$ & $\begin{array}{l}\text { Hypertonic saline } \\
\text { with Aetoxisclerol 2\% }\end{array}$ & 1 & 1 year & $\begin{array}{l}\text { Complete } \\
\text { resolution }\end{array}$ \\
\hline 10 & $\begin{array}{l}13 \\
\text { years }\end{array}$ & Female & 3 months & Left parotid & $23 \times 21$ & $\begin{array}{l}\text { Hypertonic saline } \\
\text { with Aetoxisclerol 2\% }\end{array}$ & 2 & 9 months & $\begin{array}{l}\text { Complete } \\
\text { resolution }\end{array}$ \\
\hline 11 & $\begin{array}{l}45 \\
\text { years }\end{array}$ & Female & 2 months & Right parotid & $53 \times 42$ & Absolute alcohol & 2 & 5 years & $\begin{array}{l}\text { Significant } \\
\text { regression }\end{array}$ \\
\hline 12 & $\begin{array}{l}\text { At } \\
\text { birth }\end{array}$ & Female & 12 months & $\begin{array}{l}\text { Right laterocervical } \\
\text { region }\end{array}$ & $39 \times 19$ & $\begin{array}{l}\text { Hypertonic saline } \\
\text { with Aetoxisclerol 2\% }\end{array}$ & 1 & $\begin{array}{l}\text { Lost to } \\
\text { follow-up }\end{array}$ & $\begin{array}{l}\text { Lost to follow- } \\
\text { up }\end{array}$ \\
\hline
\end{tabular}

involvement in our patients. No predilection for the side was observed.

Imaging options included US, CT scanning, and MRI. Ultrasonography is the technique of first choice in this type of lesions in order to identify the lesion and to define its structural cystic-type characteristics. It is also useful for monitoring the non-operated lesions in the case of therapeutic abstention, for postoperative surveillance, to evaluate the efficacy of the sclerotherapy and to detect the recurrences. This imaging exam is limited in its ability to define the lesions' deep extension $[9,10]$. Typically, LM appear on US as thin-walled, hypoechoic, and multiloculated cystic masses with septa of variable thickness and no blood flow on color Doppler ultrasound. They may contain echogenic fluid or fluid-fluid levels when a recent hemorrhage is present because hemorrhage leads to increased echogenicity [11, 12]. Seven of the 10 patients who underwent US in this study had anechoic masses.
CT scan demonstrates well the extent of the swelling and its relationship to the airway and other adjacent structures. It shows these lesions as unilocular or multilocular masses of differing sizes with smooth and uniform septations that enhance following bolus injection of contrast agent with regular margins [13, 14]. Three patients underwent CT examination that showed wellcircumscribed and hypodense masses with homogeneous internal density.

Although less available than CT, MRI allowed a clear evaluation of the lesion morphology and structure. The MRI sequences show the masses as hypo-intense on $\mathrm{T} 1 \mathrm{~W}$ sequences and hyper-intense on $\mathrm{T} 2 \mathrm{~W}$ sequences, suggesting fluid content, with regular margins, thin walls, and internal septa. After gadolinium administration, only the walls and the internal septa show an increased signal intensity on T1W sequences without internal contrast enhancement [15]. In our series, 6 patients underwent an MRI examination.
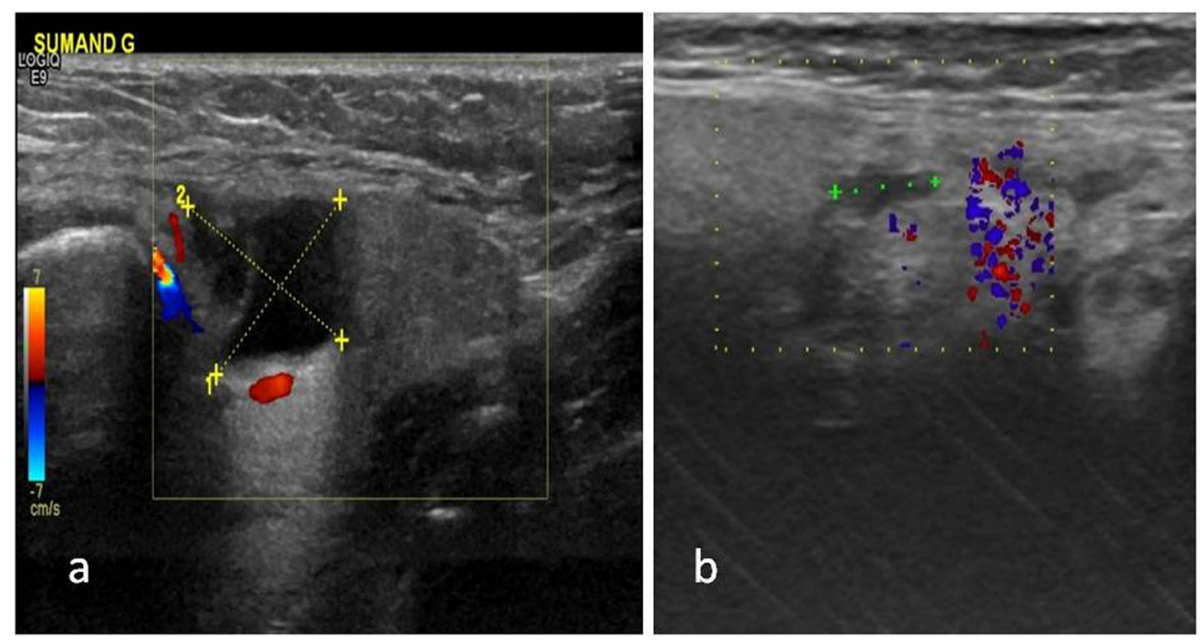

Fig. 4 Cervical color Doppler ultrasound: intermediate result 1 month after a session of sclerotherapy (a) and final outcome 4 months later (b) 
Various modalities have been described to treat CFLM. They include observation, surgical, and non-surgical management [8]. There is no consensus regarding these lesions' treatment and no accepted guidelines exist to date. A spontaneous regression is observed in $15 \%$ of lesions according to some studies [16]. On the basis of this possibility, some physicians opt to manage the asymptomatic lesions conservatively for at least 18 months to 2 years. This attitude requires extreme vigilance in managing these lesions because acute enlargement in size can occur as previously mentioned $[11,16]$. In our study, the average time between first consultation and first management was 4.5 months. During that period, no patient showed a spontaneous regression.

Complete surgical excision has been the treatment of choice for CFLM. However, due to the infiltrating nature of these lesions and the close proximity of vital structures in the head and neck area, this can be very challenging, making total extirpation nearly impossible. For this reason, injuries of adjacent neurovascular structures during surgery are frequent $[11,16]$. Total removal is usually successful with small lesions that do not involve the oral cavity.

The recurrence rate, following complete excision, ranges from 0 to $27 \%$ of the cases. After partial excision, the recurrence rate ranges from 50 to $100 \%$. Most recurrences occur within the first year of resection, but delayed recurrences as long as 10 years after the initial operation have been reported $[11,16,17]$.

Complications from surgical excisions are well documented and occur in $30 \%$ or more of cases. The most common postoperative complication is seroma which can be expected to resolve spontaneously within 10 days on average after the operation. Cranial nerve weakness is the next most common complication. It can occur in up to a third of these CFLM treated surgically with the marginal mandibular branch of the facial nerve most frequently involved [16]. Facial paresis is transient in most cases and resolves by medical treatment by an average of 2 months. Frey and Horner's syndromes, Muscle weakness, and life-threatening infections such as mediastinitis and sepsis are also documented as postoperative complications [18].
In our study, seven patients were treated surgically. Resection was total in six patients and partial only in one patient. The recurrence of the disease was observed in one patient 6 months after incomplete resection of the lesion. The only complication observed was a reversible paresis of the left mental nerve in one patient with a left submandibular lesion.

Among the treatments available as alternatives to surgery, the most widely experimented on in patients is sclerotherapy. The current literature reports the efficiency of this therapeutic modality, especially for macrocystic lesions. It is currently considered as the first-line therapy for this type of lesions, sometimes in combination with surgical debulking. Intralesional injection of sclerosing agent damages the endothelium, and this is followed by inflammation, thrombotic vascular occlusion, and sclerosis with regression of the lesion [19]. Frequently, several injections of sclerosing agents are needed [20].

To date, a wide range of sclerosing agents have been used in daily practice, but it is unclear which sclerosing agent is superior in terms of safety and effectiveness. This is partly due to a lack of understanding on the sclerosant mechanism of action $[19,21]$. The sclerosing agents used in our patients were Aetoxisclerol 2\%, hypertonic saline solution, and absolute alcohol.

In this therapeutic modality, response to treatment depends on the sclerosing agent injected into the lesions as shown in Table 5.

Complication rates in sclerotherapy seem to be low. Inflammatory response, flu-like symptoms, and induration of the skin in the injection site are the most common complications. Some specific complications according to sclerosing agents were documented. In this study, complete resolution was noted in three cases with no recurrence of the disease whereas a minimal residual was observed in one case. The average number of injections was 1.4. The complications observed were a mild temperature elevation in one patient, a local inflammatory reaction in one patient, and intralesional hemorrhage in one patient.

Finally, through our study and review of literature, we propose this decision tree for the management of CFLM (Fig. 5).

Table 5 Response to sclerotherapy according to sclerosing agents

\begin{tabular}{llll}
\hline Sclerosing agent & $\begin{array}{l}\text { Study(ies) } \\
\text { First author }\end{array}$ & Average Nbr of injections & Overall response \\
\hline OK-432 & Giguère [11], Yoo [22], Horbach [19] & 2 & $83.5-96 \%$ \\
Bleomycin & Horbach [19] & $3-4$ & $70-100 \%$ \\
Doxycycline & Horbach [19] & $1-1.6$ & $67-100 \%$ \\
Ethibloc & Emran [23] & $1-6$ & $77-84 \%$ \\
Polidocanol & Horbach [19] & $2-3$ & $90-100 \%$ \\
Absolute ethanol & Horbach [19] & Not reported & $68-100 \%$ \\
\hline
\end{tabular}




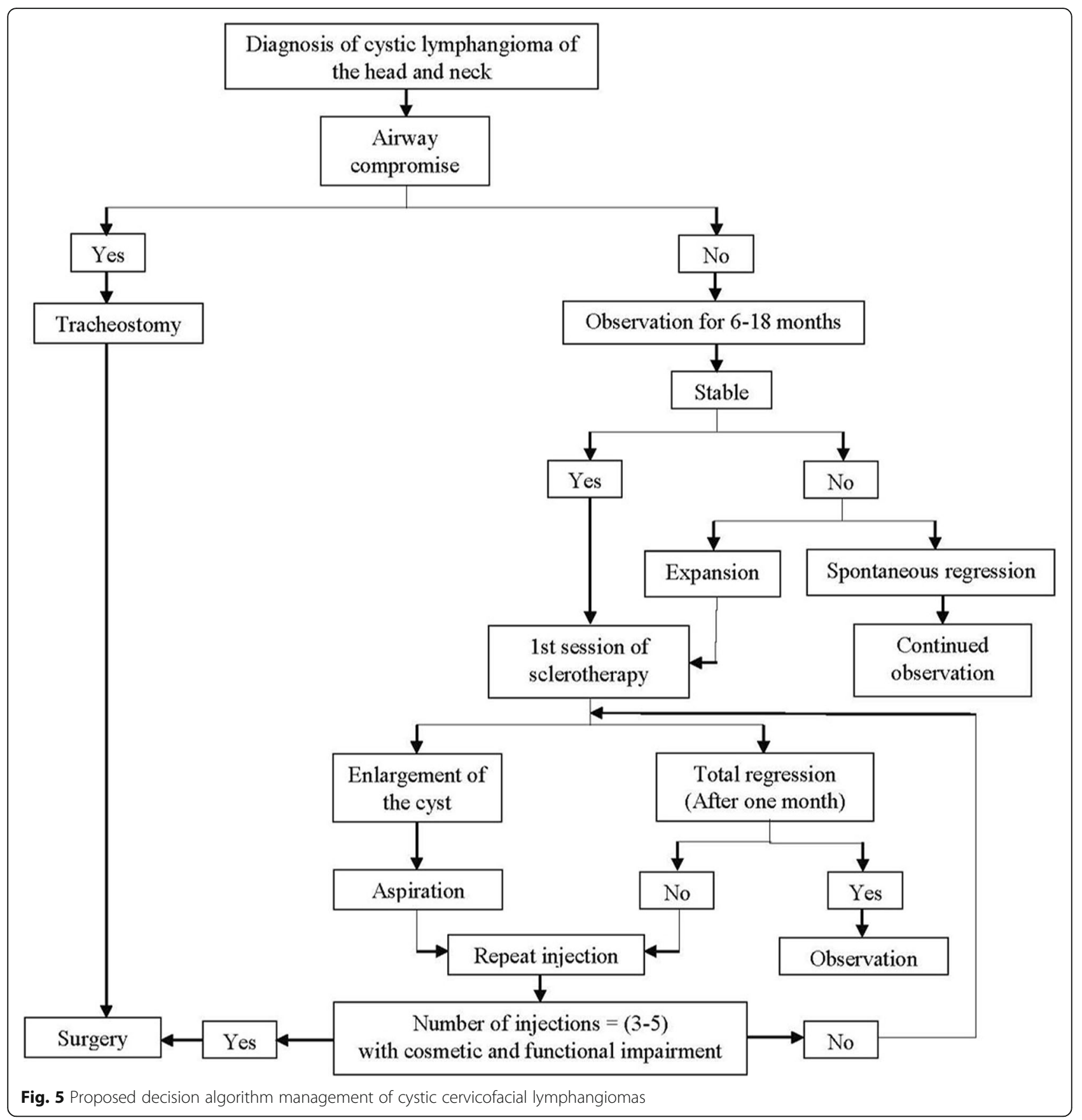

\section{Conclusions}

In conclusion, this series shows that sclerotherapy for a CFLM is well tolerated. It is associated with excellent or satisfactory results. The relatively low complication rate of sclerotherapy in these lesions makes it a good alternative to surgical intervention. Moreover, it does not preclude surgery if needed.

\section{Abbreviations}

LM: Lymphatic malformations; LMHN: Lymphatic malformations of the head and neck; CFLM: Cervicofacial lymphatic malformations; CT: Computed tomography; MRI: Magnetic resonance imaging; T1W: T1-weighted; T2W: T2weighted

\section{Acknowledgements}

Not applicable.

Authors' contributions

$\mathrm{RB}$ : redaction of the manuscript and the corresponding author. HBa: performed the imaging exams and correction of the radiologic part. MHa: analyzed and interpreted the patient data and wrote the manuscript. AF: a major contributor in bibliographic search. KH: revision of the manuscript. NKo: a major contributor in correcting the manuscript. Jk: final revision and approval of the manuscript. All authors have read and approved the final manuscript. 


\section{Funding}

No funding was obtained for this study.

\section{Availability of data and materials}

The datasets during and/or analyzed during the current study are available from the corresponding author on reasonable request.

\section{Declarations}

\section{Ethics approval and consent to participate}

This is a retrospective study approved by the Institutional Ethics Committee of the University of Monastir, Tunisia, IORG 0009738/0990-0279.

This is a retrospective study so that participants did not provide informed consent.

\section{Consent for publication}

Written informed consent for publication of the clinical image was obtained from the patient's parent.

\section{Competing interests}

The authors declare that they have no competing interests.

\section{Author details}

ENT Department at Fattouma Bourguiba Hospital, Monastir, Tunisia. ${ }^{2}$ University of Monastir, Monastir, Tunisia. ${ }^{3}$ Department of Radiology at Fattouma Bourguiba Hospital, Monastir, Tunisia.

\section{Received: 5 January 2021 Accepted: 10 June 2021}

Published online: 28 July 2021

\section{References}

1. Kotsis T, Exarchos G, Metaxa L, Triantos S (2018) Recurrent neck lymphangioma in a young adult: twenty-three years after successful treatment. Vasc Endovascular Surg 29:1538574418814057

2. Divya PGA (2015) Cystic hygroma - a case report and its embryological basis. Anat Physiol 05(01). https://doi.org/10.4172/2161-0940.1000169

3. Munteanu O, Cîrstoiu MM, Filipoiu FM, BohîTTea RE, Bulescu IA, Berceanu C (2016) Morphological and ultrasonographic study of fetuses with cervical hygroma. A cases series. Romanian J Morphol Embryol Rev Roum Morphol Embryol 57(4):1421-1427

4. Sardhara J, Mehrotra A, Singh AK, Sindgikar $P$, Shukla M, Chovatiya $P$, Bhaishora K, K Das K, Srivastava A, Behari S (2016) Bilateral cervical lymphangioma of the neck in an adult: a rare case with review of literature. IOSR J Dent Med Sci 15(08):117-121. https://doi.org/10.9790/ 0853-150811117121

5. Abdur-Rahman L, Awolaran O, Nasir A, Bamigbola KT, Abdulraheem NT, Oyinloye AO, Adeniran JO (2017) Efficacy of bleomycin for non-operative treatment of cervical lymphangioma in University of Ilorin Teaching Hospital, Nigeria. J Med Trop 19(2):93. https://doi.org/10.4103/jomt. jomt_14_17

6. Orvidas LJ, Kasperbauer JL (2000) Pediatric lymphangiomas of the head and neck. Ann Otol Rhinol Laryngol 109(4):411-421

7. Noia G, Maltese PE, Zampino G, D'Errico M, Cammalleri V, Convertini P, Marceddu G, Mueller M, Guerri G, Bertelli M (2019) Cystic Hygroma: A Preliminary Genetic Study and a Short Review from the Literature. Lymphat Res Biol 17(1):30-39. https://doi.org/10.1089//rb.2017.0084.

8. Balogun O, Osinowo A, Afolayan M, Olajide T (2017) Surgical management of acquired cervical cystic hygroma in a Nigerian adult. J Case Rep 20:260-263

9. Grasso DL, Pelizzo G, Zocconi E, Schleef J (2008) Lymphangiomas of the head and neck in children. Acta Otorhinolaryngol Ital 28(1):17-20

10. Linnaus ME, Notrica DM (2016) Infected cystic hygroma resulting in septic shock and respiratory failure: a case report. J Pediatr Surg Case Rep 9:19-22. https://doi.org/10.1016/j.epsc.2016.04.005

11. Giguère CM, Bauman NM, Smith RJH (2002) New treatment options for lymphangioma in infants and children. Ann Otol Rhinol Laryngol 111(12): 1066-1075. https://doi.org/10.1177/000348940211101202

12. Mittal M, Malik A, Sureka B, Thukral B (2012) Cystic masses of neck: a pictorial review. Indian J Radiol Imaging 22(4):334-343. https://doi.org/10.41 03/0971-3026.111488
13. Chinnakkulam Kandhasamy S, Ramasamy Raju T, Sahoo AK, Gunasekaran G (2018) Adult cystic lymphangioma of the parotid gland: an unwonted presentation. Cureus 10(5):2644

14. Gaddikeri S, Vattoth S, Gaddikeri RS, Stuart R, Harrison K, Young D, Bhargava P (2014) Congenital cystic neck masses: embryology and imaging appearances, with clinicopathological correlation. Curr Probl Diagn Radiol 43(2):55-67. https://doi.org/10.1067/j.cpradiol.2013.12.001

15. Romeo V, Maurea S, Mainenti PP et al (2015) Correlative imaging of cystic lymphangiomas: ultrasound, CT and MRI comparison. Acta Radiol Open 4(5): 2047981614564911

16. Oosthuizen JC, Burns P, Russell JD (2010) Lymphatic malformations: a proposed management algorithm. Int J Pediatr Otorhinolaryngol 74(4):398403. https://doi.org/10.1016/j.ijporl.2010.01.013

17. Lei Z-M, Huang X-X, Sun Z-J, Zhang W-F, Zhao Y-F (2007) Surgery of lymphatic malformations in oral and cervicofacial regions in children. Oral Surg Oral Med Oral Pathol Oral Radiol Endod 104(3):338-344

18. Khanwalkar A, Carter J, Bhushan B, Rastatter J, Maddalozzo J (2018) Thirtyday perioperative outcomes in resection of cervical lymphatic malformations. Int J Pediatr Otorhinolaryngol 106:31-34. https://doi.org/10.1 016/j.ijporl.2017.12.034

19. Horbach SER, Lokhorst MM, Saeed P, de Goüyon Matignon de Pontouraude CMF, Rothová A, van der Horst CMAM (2016) Sclerotherapy for low-flow vascular malformations of the head and neck: a systematic review of sclerosing agents. J Plast Reconstr Aesthet Surg 69(3):295-304. https://doi. org/10.1016/j.bjps.2015.10.045

20. Deveikis JP (2005) Percutaneous ethanol sclerotherapy for vascular malformations in the head and neck. Arch Facial Plast Surg 7(5):322

21. Perkins JA, Manning SC, Tempero RM, Cunningham MJ, Edmonds JL Jr, Hoffer FA, Egbert MA (2010) Lymphatic malformations: review of current treatment. Otolaryngol-Head Neck Surg 142(6):795-803. https://doi.org/10.1 016/j.otohns.2010.02.026

22. Yoo JC, Ahn Y, Lim YS et al (2009) OK-432 Sclerotherapy in head and neck lymphangiomas: long-term follow-up result. Otolaryngol-Head Neck Surg 140(1):120-123

23. Emran MA, Dubois J, Laberge L, Al-Jazaeri A, Bütter A, Yazbeck S (2006) Alcoholic solution of zein (Ethibloc) sclerotherapy for treatment of lymphangiomas in children. J Pediatr Surg 41(5):975-979. https://doi.org/1 0.1016/j.jpedsurg.2006.01.019

\section{Publisher's Note}

Springer Nature remains neutral with regard to jurisdictional claims in published maps and institutional affiliations.

\section{Submit your manuscript to a SpringerOpen ${ }^{\circ}$ journal and benefit from:}

- Convenient online submission

- Rigorous peer review

- Open access: articles freely available online

- High visibility within the field

Retaining the copyright to your article

Submit your next manuscript at $\boldsymbol{\nabla}$ springeropen.com 